Research Article

\title{
Mechanism of Hydraulic Fracturing Cutting Hard Basic Roof to Prevent Rockburst
}

\author{
Jianqiao Luo $\mathbb{D}^{1},{ }^{1}$ Shaohong Yan ${ }^{D},{ }^{1}$ Tuo Yang, ${ }^{1}$ Haoqi Mu, ${ }^{1}$ Wensheng Wei, ${ }^{1}$ \\ Yupeng Shen, ${ }^{1}$ and Hongtao $\mathrm{Mu}^{2}$ \\ ${ }^{1}$ School of Energy and Mining Engineering, China University of Mining and Technology (Beijing), Beijing 100083, China \\ ${ }^{2}$ General Prospecting Institute China National Administration of Coal Geology, Beijing 100039, China \\ Correspondence should be addressed to Shaohong Yan; 455244958@qq.com
}

Received 17 July 2021; Accepted 3 September 2021; Published 10 November 2021

Academic Editor: Xiao Wang

Copyright (C) 2021 Jianqiao Luo et al. This is an open access article distributed under the Creative Commons Attribution License, which permits unrestricted use, distribution, and reproduction in any medium, provided the original work is properly cited.

Rockburst is globally regarded as one of the most severe and complicated mining dynamic disasters to predict or control. Generally, the occurrence mechanism of rockbursts can be considered as a process of the elastic strain energy accumulation, emancipation, transmission, and occurrence. Tracing to the source, the reasons for large accumulation of elastic strain energy in coal and rock mass are the high stress of the roof layer that loads on the coal and rock masses around the mining space coupling effect with the natural horizontal tectonic stress. In this study, using the minimum energy theory and elasticity theory, the analytical formula for calculating elastic strain energy of the roof cantilever beam structure acting on the coal body load in front of the working face is deduced. Accordingly, we achieved a method of using hydraulic fracturing to improve the roof structure. In detail, we use a high-pressure jet to cut the cantilever roof structure, which can make a prelocated fracture surface, and then utilize the packers to make sure that the injected high-pressure fracturing fluid is propagating along the prelocated fracture surface and can cut off the cantilever roof structure eventually to prevent rockbursts in advance. Due to the rockburst occurrence mechanism and the quantitatively elastic strain energy analytical formula, a preconditioning water jet cutting induced fracture surface to create orientation-controllable hydraulic fracture strategy is proposed to guard against the high hazard caused by the massive elastic strain energy, which accumulated in the coal body in front of the working face and coal pillar.

\section{Introduction}

Rockbursts are an instantaneous release of elastic energy of an overstressed coal and rock mass and have been recognized as one of the most critical dynamic failures in coal mines [1-6]. In March 2021, more than 27 mines were ordered to be shut down, which are at great risk of rockbursts $[7,8]$. The remaining reserves of these 27 coal mines reach 1,510,027,000 tons, and the loss of these coal resources value is about 180 billion U.S. dollars. And the annual capacity loss reached 34 million tons, which is worth about 2.7 billion dollars.

In recent decades, although the prediction and prevention methods has captured global attention and achieved rapid development, the actual mechanism of rockburst process remains unclear yet; especially, the elastic strain energy quantitative solution to describe the rockburst propensity for the surrounding rock mass and the coal body needs to be derived urgently.

Since there are many factors affecting the occurrence of rockbursts, including in situ stress, mechanical properties of coal and surrounding rock, seismic disturbance, and engineering structure [9-17], it is not completely reliable to predict the rockburst hazard by relying solely on the impact tendency of coal, rock, or coal-rock composite specimens. Thus, to consider whether the specific position in the surrounding coal or rock mass of the caving space has a critical risk of rockbursts, more efforts should be devoted to investigating the source of high redistributed stress, especially considering the source as two aspects, static load stress and dynamic load stress, where the principle of minimum energy [18] can be 
applied to quantify the elastic strain energy field in the surrounding coal and rock mass. Therefore, this study investigates the exact numerical value in the surrounding coal body and rock mass around the extract space.

Although many international scholars and experts have proposed a bunch of theories on rockburst occurrence hazard and its prevention method [15], the prediction and calculation of rockburst occurrence hazard are still a serious challenge [16]. Including the "strength theory" [6], "stiffness theory" (Hudson et al., 1972), "energy theory" (Salamon, 1964), "rockburst tendency theory" (Singh, 1988), "three factors theory" (Qi, 1997), and "rockburst starting theory" (Pan et al., 2012). These theories criteria reveal the qualitative mechanism between the initiation, transmission, and manifestation of rockbursts and the conditions of related factors sufficiently. However, the quantitative understanding of the elastic strain energy and its evolution law has not been researched thoroughly. Based on the research status above, the objective of our work is to investigate the quantized impact that dynamic load stress and static load stress on the elastic strain energy in the surrounding coal body and rock mass around the extract space. First, we establish mechanical model of roof cantilever structure. Then, a quantitative description formula of elastic strain energy, which plays a decisive role in the whole process of rockburst, is derived. According to the elastic strain energy formula, the law of its evolution, when the working face continues to mining forward and the overlying strata move repeatedly, is obtained.

To this end, conducting hydraulic fracture method to weaken the roof structure is a feasible technique to decrease the elastic strain energy in the high rockburst hazard position. Due to the extra-thick and rigid rock properties of basic roof, a number of induced fracturing surfaces should be preset by water jet cutting method at the target position. In doing so, continuous basic roof rock mass will be cut off by fracture surface, and the rockburst potential of the region below the hydraulic fracturing location is reduced obviously $[19,20]$.

\section{Occurrence Mechanism and Process of the Coal Body Rockbursts}

Over recent years, rockbursts had an increasingly bad influence on Chinese coal mines and had proven to be the most significant and complex dynamic phenomenon in mine engineering. Elastoplasticly speaking, rockburst of coal body or rock mass is due to the reason that coal body or rock mass was compressed to the three-dimensional strength limit. Then, striking failures and destructions occur in coal body or rock mass, which consume part of elastic strain energy stored in the coal body and rock mass originally. The rest of elastic strain energy impacts the adjacent coal body and rock mass by mechanical work elastic wave (see Figure 1).

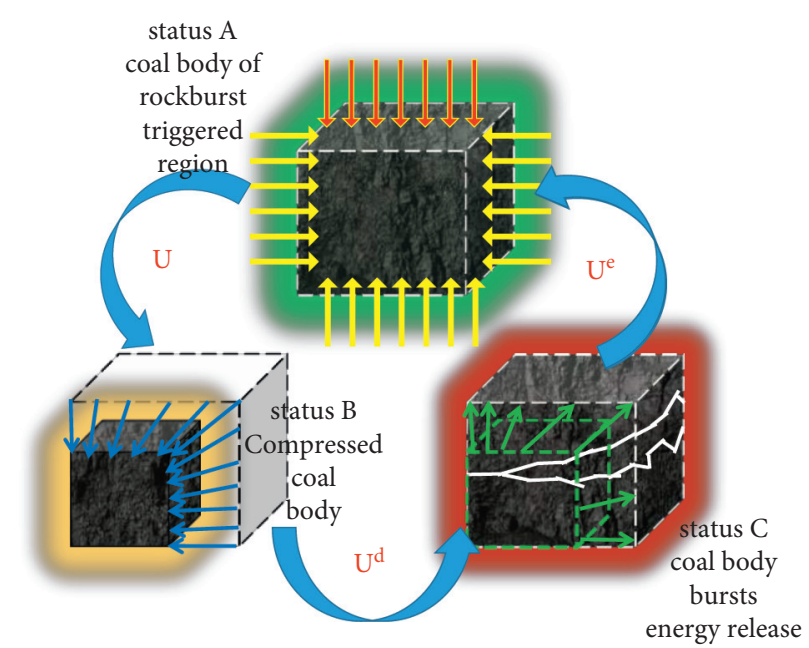

FIGURE 1: Energy transfer form of elastic strain between microcoal and rock mass.

We name the main energy-releasing body of a selfinitiated or external dynamic load-triggered rockburst as coal body A. After coal body A is destroyed by the excessive external stress, part of the elastic strain energy stored in A will transfer to the adjacent coal body, which is called coal body B. B is in limit equilibrium originally before the elastic energy from coal body A affected. After the transmission, coal body $B$ is no longer in limit equilibrium, but cracking caused by the severely mechanical work from coal body A. And the elastic strain energy stored in $\mathrm{B}$ will be released to affect the adjacent coal body $\mathrm{C}$, just like the process when coal body $\mathrm{A}$ is affecting $\mathrm{B}$. The transfer process from $\mathrm{A}$ to $\mathrm{B}$ to $\mathrm{C}$ is like a repetitive chain-type cycle, as shown in Figure 2.

Through the "chain-type" energy transfer between the microcoal body units, the broken coal near the working face was impacted into the mining working face forcibly. Determined by the ultimate elastic strain energy, the severity of rockbursts in the working face or roadways can be predicted to a certain extent. Focusing on the solution of the elastic strain energy stored in the unit coal body in front of the working face, three-dimensional stress $\left(\sigma_{v}, \sigma_{H}, \sigma_{h}\right)$ and principal stresses $\left(\sigma_{1}, \sigma_{2}, \sigma_{3}\right)$ need to be quantified by a series of constitutive relation equations using elastic mechanics. According to the measurement results of in situ stress in some typical mining areas in Shanxi province, China, estimation formulas of in situ stress were obtained [7]:

$$
\left\{\begin{array}{l}
\sigma_{v}=24500 H, \\
\sigma_{H}=21500 H+3267000, \\
\sigma_{h}=11300 H+1954000 .
\end{array}\right.
$$

According to the equilibrium condition, $\sum M_{A}=0$; $\sum M_{A}=0$, and short cantilever beam force acting on hinged rock block of coal body in front of working face can be obtained: 


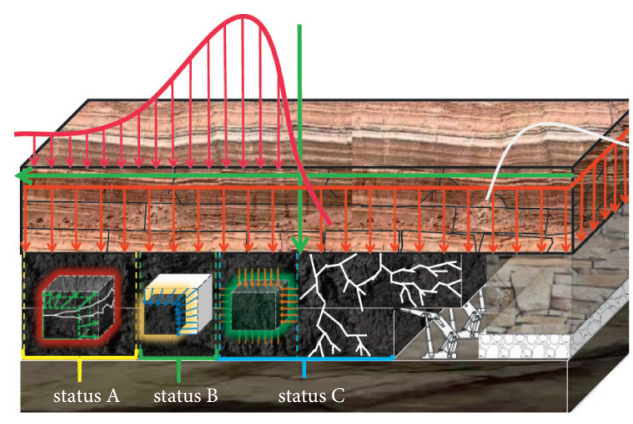

(a)

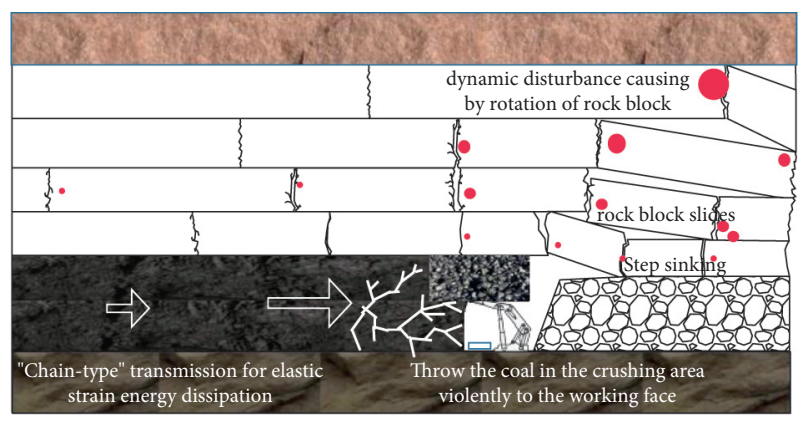

(b)

FIGURE 2: A-B-C coal body "chain-type" energy transfer process. (a) Zoning diagram of rock energy storage state. (b) Diagram of energy transfer process of rockburst.

$$
\left\{\begin{array}{l}
F_{A B}=\frac{F_{i} L_{B} \sin \theta+P_{B}\left(L_{B}+h \tan \theta\right)}{2 L_{B}+2 h \tan \theta}, \\
F_{i}=\left(H_{i} \cot \alpha+\frac{L}{2}\right) H_{1} \gamma g, \\
L_{B}=\frac{2 L^{\prime}}{17}\left[\sqrt{\left(10 \frac{L^{\prime}}{L}\right)^{2}+102}-10 \frac{L^{\prime}}{L}\right], \\
L^{\prime}=2 h \sqrt{\frac{R_{T}}{3 q}} .
\end{array}\right.
$$

The concentrated force $F_{B}$ of short cantilever beam in front of the working face:

$$
F_{B}=\left[\sum_{i=1}^{n} P_{i} L_{i}+\sum_{i=1}^{n} P_{i} h_{i} \cot \beta+2 \sum_{j=2}^{n} \sum_{i=1}^{j-1} P_{i} h_{i} \cot \beta+F_{A B}\left(l_{n}+2 \sum_{i=1}^{n} h_{i} \cot \beta \cos \theta\right)\right],
$$

where $H$ is buried depth; $\sigma_{v}, \sigma_{H}, \sigma_{h}$ are three in situ principal stresses ( $\sigma_{v}$ along the vertical direction; and $\sigma_{H}$ and $\sigma_{h}$ along two mutually orthogonal horizontal directions with maximum and minimum values, respectively) of the calculated unit coal body before mining activities; $L$ is the length of the working face; $H_{1}$ is the thickness of the bending-subsidence layer; $H_{i}$ is the accumulated height from the bending-subsidence layer to the roof of the coal seam; $\alpha$ is the angle of stratum movement; $\theta$ is the rotation angle of the cantilever beam structure; $L_{B}$ is the fracture length of the key block; and $R_{T}$ is the tensile strength of the cantilever beam structure.

In equation (3), $P_{1}$ is the weight of main roof broken rock block; $P_{2} \sim P_{n}$ are stresses of each layer moving with the main roof strata, respectively; $l_{1}$ is the fracture length of the direct roof rock strata; $l_{2} \sim l_{n}$ are the fracture lengths of each rock stratum overlying the direct roof, respectively; $\beta$ is the fracture angle of rock strata. 
Combined with the Mohr-Coulomb criterion and elastoplastic theory, we introduce formula (2) into formula (3) to simplify the form:

$$
\left\{\begin{array}{l}
F_{B}=\frac{1}{2 x_{0}}\left(R_{T}+R_{T} \cot \beta+2\left(R_{T}-R_{T}^{\prime}\right) \cot \beta+F_{A B}\left(x_{0}+2 h_{i} \cot \beta \cos \theta\right)\right) \\
x_{0}=\frac{M}{2 f}\left(\frac{1+\sin \varphi}{1-\sin \varphi}\right) \ln \left[\frac{K \gamma H}{\tau_{0} \cot \varphi}\left(\frac{1-\sin \varphi}{1+\sin \varphi}\right)\right]+\frac{M v}{2 f} \cdot \ln K
\end{array}\right.
$$

where $R_{T}^{\prime}$ is the tensile strength of the rock strata overlying the direct roof short cantilever beam hinged structure; $M$ is the thickness of the coal seam; $\varphi$ is the internal friction angle; $K$ is the coefficient of stress concentration; and $v$ is the coefficient of horizontal pressure.

The mechanical model of key block and cantilever beam is shown in Figure 3:

By analyzing the formulas above, the stress and strain field distribution in the coal seam in front of the caving space can be obtained, where the rockburst occurrence results in high hazard and high elastic strain energy stored zone, precisely.

\section{Elastic Strain Energy and Stress Distribution Analytical Solution in Status A and Status B}

Based on the energy theory and elastic mechanics, the failure of rock material is the result of energy conversion [16]. Assuming that a unit volume of material deforms by outer stress and load in a closed system, the energy conversion can be defined according to the first law of thermodynamics as

$$
U=U^{e}+U^{\mathrm{d}}
$$

where $U$ is the energy done by the external stress and $U^{e}$ and $U^{d}$ are the elastic strain energy and dissipation energy, respectively. For the intact rock mass and coal body, $U^{e}$ can be calculated by the following formula:

$$
U^{e}=\frac{1}{2 E}\left[\sigma_{1}^{2}+\sigma_{2}^{2}+\sigma_{3}^{2}-2 \mu\left(\sigma_{1} \sigma_{2}+\sigma_{2} \sigma_{3}+\sigma_{3} \sigma_{1}\right)\right],
$$

where $\sigma_{1}, \sigma_{2}$ and $\sigma_{3}$ are the total stresses in the three principal stress directions, respectively; $E$ is elastic modulus, $\mathrm{GPa}$; and $\mu$ is Poisson's ratio.

Thus, we need to conduct a derivation using formulas (3) and (4) to obtain the values of $\sigma_{1}, \sigma_{2}$ and $\sigma_{3}$; after that, we can determine the elastic strain energy distribution in status $\mathrm{A}$ and status B zones as in Figure 4.

Based on the elastoplastic mechanics and its superposition principle, assume the unit coal body in zone $\mathrm{A}$ and $\mathrm{B}$ as homogeneous, isotropic, and intact coal. Stress curve of $\sigma_{z}$ in front of the working face can be simplified as two straight lines. And the function expressions of these two straight lines can be obtained by method of undetermined coefficient with the three coordinates [21]: $\left(0, q_{1}-\gamma \mathrm{H}\right),\left(x_{0}, \mathrm{~K} \gamma \mathrm{H}\right)$ and $\left(L_{2}, 0\right)$. At this time, the principal stresses of any unit $M(x, y)$ of coal seam under the stress curve can be obtained as those aforementioned in formula (6):

Incremental stress in the vertical direction $\Delta \sigma_{y}$ :

$$
\left\{\begin{array}{l}
\Delta \sigma_{y i}=\int_{0}^{L_{i}}-\frac{2\left(k_{i} \xi+b_{i}\right)}{\pi} \cdot \frac{y^{3} d \xi}{\left[(x-\xi)^{2}+y^{2}\right]^{2}} \\
=\Delta \sigma_{y 1}+\Delta \sigma_{y 2}+\gamma H=-\frac{\left(k_{1} x+b_{1}\right)}{\pi} \cdot\left[\arctan \left(\frac{x}{y}\right)-\arctan \left(\frac{x-L_{2}}{y}\right)+\frac{x y}{x^{2}+y^{2}}-\frac{y\left(x-L_{1}\right)}{\left(x-L_{1}\right)^{2}+y^{2}}\right] \\
-\frac{k_{1} y^{3}}{\pi}\left[\frac{1}{x^{2}+y^{2}}-\frac{1}{\left(x-L_{1}\right)^{2}+y^{2}}\right] \\
-\frac{\left(k_{2} x+b_{2}\right)}{\pi}\left[\arctan \left(\frac{x-L_{1}}{y}\right)-\arctan \left(\frac{x-L_{2}}{y}\right)+\frac{y\left(x-L_{1}\right)}{\left(x-L_{1}\right)^{2}+y^{2}}-\frac{y\left(x-L_{2}\right)}{\left(x-L_{2}\right)^{2}+y^{2}}\right] \\
-\frac{k_{2} y^{3}}{\pi}\left[\frac{1}{\left(x-L_{1}\right)^{2}+y^{2}}-\frac{1}{\left(x-L_{2}\right)^{2}+y^{2}}\right]+\gamma H .
\end{array}\right.
$$



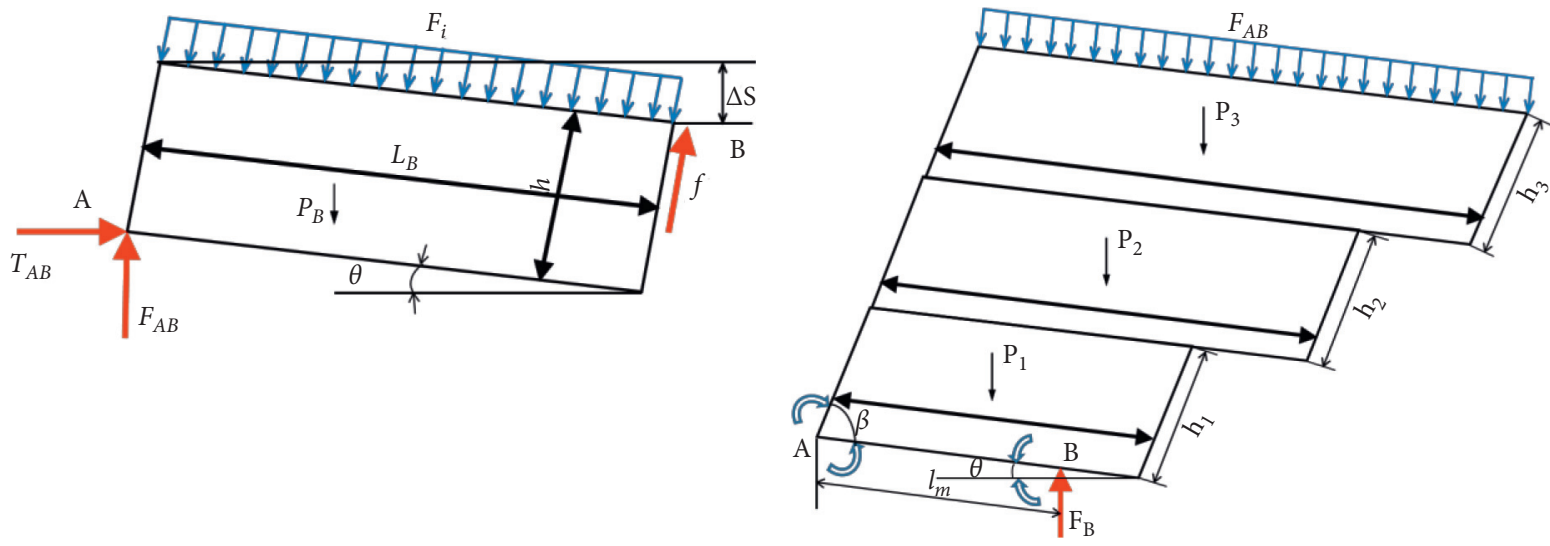

(a)

(b)

FIGURE 3: Mechanical model of the key block and cantilever beam. (a) Stress analysis of key blocks. (b) Stress analysis of cantilever structure.

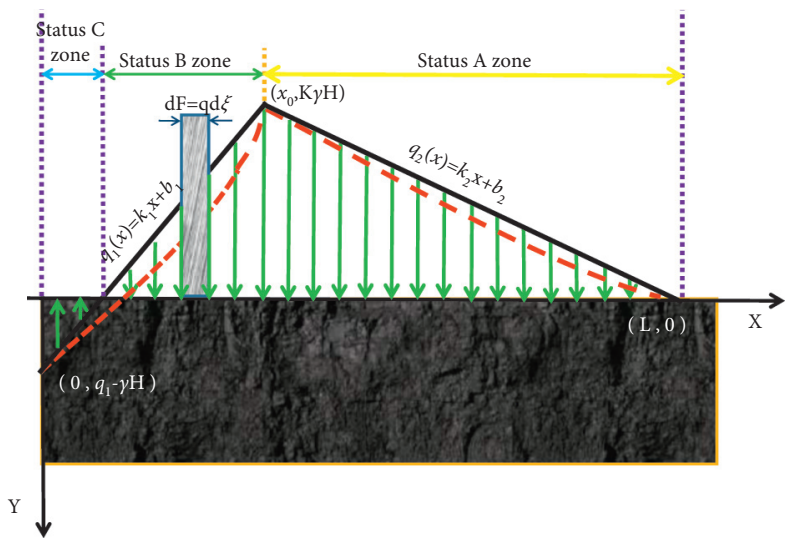

Figure 4: Mechanical model of stress calculation in zone A-B-C.

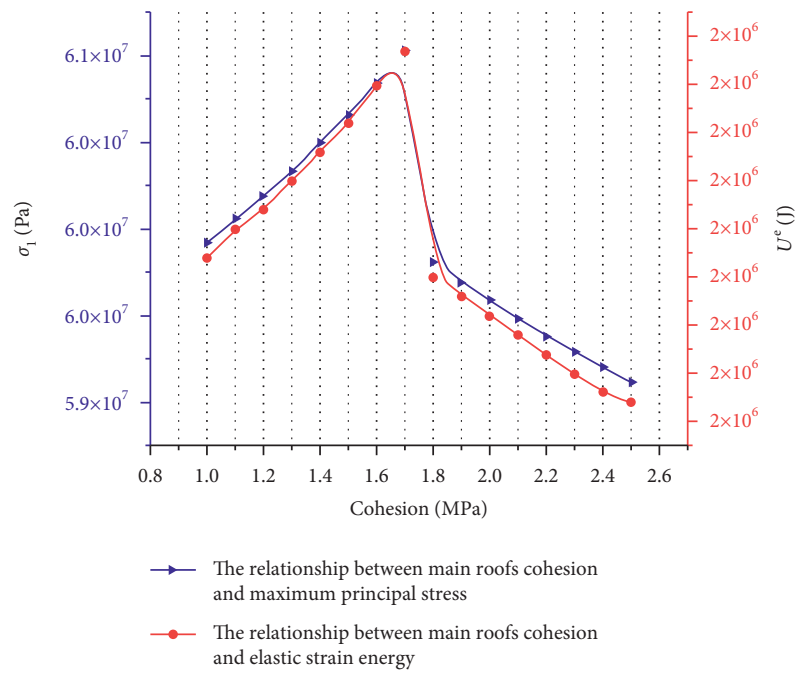

(a)

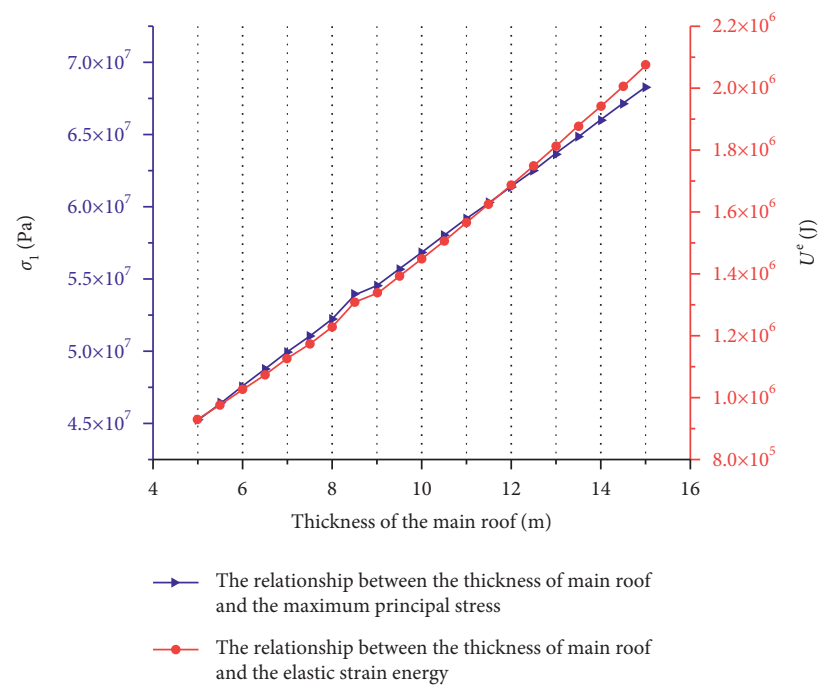

(b)

FIGURE 5: Continued. 


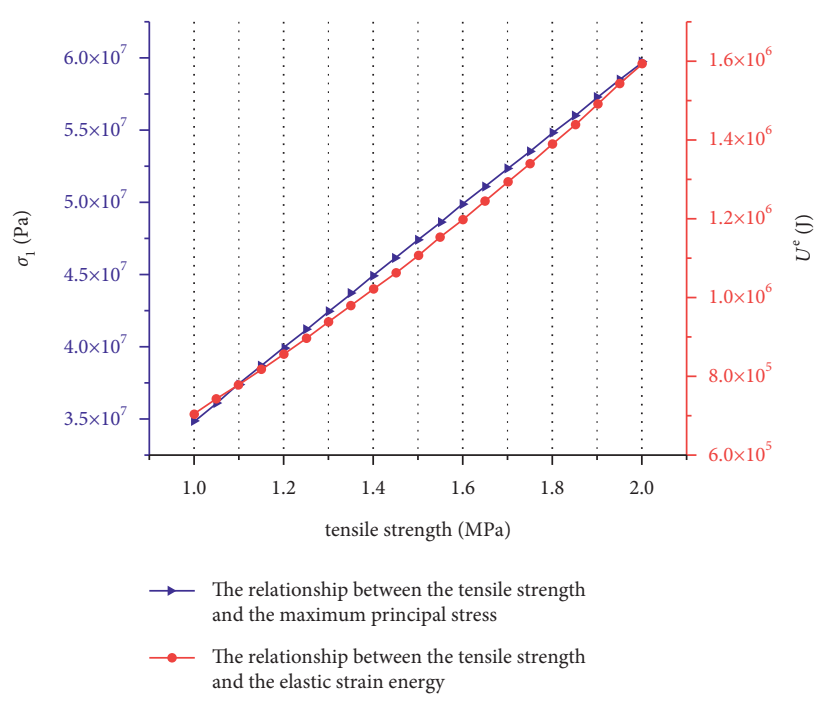

(c)

Figure 5: Relationship between three controllable factors, $\sigma_{1}$, and $U^{e}$. (a) The relationship between cohesions, $\sigma_{1}$, and $U^{e}$. (b) The relationship between thicknesses, $\sigma_{1}$, and $U^{e}$. (c) The relationship between tensile strengths, $\sigma_{1}$, and $U^{e}$.

Incremental stress in the horizontal direction $\Delta \sigma_{x}$ :

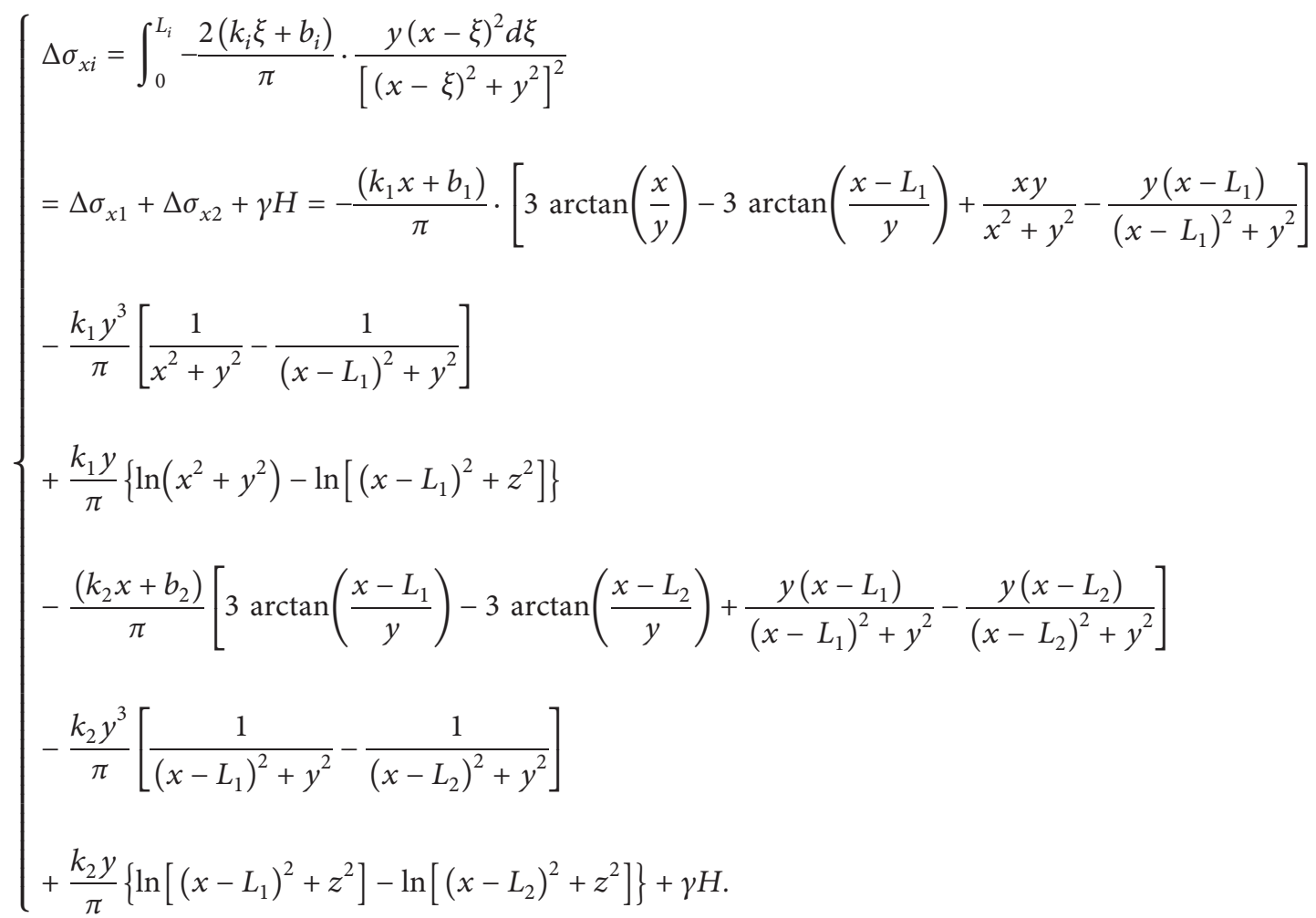

Incremental stress in the tangential direction $\Delta \tau_{x y}$ : 


$$
\left\{\begin{array}{l}
\Delta \tau_{x y_{i}}=\int_{0}^{L_{i}}-\frac{2\left(k_{i} \xi+b_{i}\right)}{\pi} \cdot \frac{y^{2}(x-\xi) d \xi}{\left[(x-\xi)^{2}+y^{2}\right]^{2}} \\
=\Delta \tau_{x y_{1}}+\Delta \tau_{x y_{2}}+\gamma H=-\frac{k_{1} y}{\pi} \cdot\left[\frac{x y}{x^{2}+y^{2}}-\frac{\left(x-L_{1}\right)}{\left(x-L_{1}\right)^{2}+y^{2}}-\arctan \frac{x}{y}+\arctan \frac{x-L_{1}}{y}\right] \\
+\frac{\left(k_{1} x+b_{1}\right) y^{2}}{\pi}\left[\frac{1}{x^{2}+y^{2}}-\frac{1}{\left(x-L_{1}\right)^{2}+z^{2}}\right] \\
-\frac{k_{2} y}{\pi}\left[\frac{y\left(x-L_{1}\right)}{\left(x-L_{1}\right)^{2}+y^{2}}-\frac{y\left(x-L_{2}\right)}{\left(x-L_{2}\right)^{2}+y^{2}}-\arctan \frac{x-L_{1}}{y}+\arctan \frac{x-L_{2}}{y}\right] \\
+\frac{2\left(k_{2} x+b_{2}\right) y^{2}}{\pi}\left[\frac{1}{\left(x-L_{1}\right)^{2}+z^{2}}-\frac{1}{\left(x-L_{2}\right)^{2}+z^{2}}\right] .
\end{array}\right.
$$

Variables in formulas (7), (8), and (9) can be expressed as

$$
\left\{\begin{array}{l}
k_{1}=\frac{(1+K) \gamma H-q_{1}}{x_{0}}, \\
k_{2}=\frac{K \gamma H}{\left(x_{0}-L_{2}\right)}, \\
L_{1}=x_{0}=\frac{M}{2 \xi f} \cdot \ln \frac{K \gamma H+C \cot \varphi}{\xi\left(p_{1}+C \cot \varphi\right)}, \\
\xi=\frac{1+\sin \varphi}{1-\sin \varphi}, \\
L_{2}=\frac{m}{2 f} \cdot\left(\frac{1+\sin \varphi}{1-\sin \varphi}\right) \cdot \ln \left[\frac{K \gamma H}{5 \times 10^{6} \times \cot \varphi}\left(\frac{1-\sin \varphi}{1+\sin \varphi}\right)\right]+\frac{m v}{2 f} \cdot \ln K \\
b_{1}=q_{1}-\gamma H, \\
b_{2}=\frac{K \gamma H L_{2}}{L_{2}-L_{1}},
\end{array}\right.
$$

where $q_{1}$ is swelling stress of the coal seam, MPa; $C$ is cohesion, MPa; $f$ is the friction factor between coal seam and roof and floor.
According to the principal stress deflection formula, using formulas (7), (8), and (9), the elastic strain energy $U^{e}$ can is obtained. Due to the lengthy formula, here is a 
simplified form that can be substituted into the aforementioned formula for calculation:

$$
\begin{aligned}
U^{e}= & \frac{1}{2 E}\left\{\left[\left(\Delta \sigma_{x}+\sigma_{H}\right)+\left(\Delta \sigma_{y}+\sigma_{v}\right) \cos \alpha\right) \sin \theta+\left(\left(\sigma_{h}+\Delta \tau_{x y}\right)+\left(\Delta \sigma_{y}+\sigma_{v}\right) \sin \alpha\right) \cos \theta\right]^{2} \\
& +\left(\left(\Delta \sigma_{x}+\sigma_{H}+\left(\Delta \sigma_{y}+\sigma_{v}\right) \cos \alpha\right)\right. \\
& \left.\cos \theta+\left(\sigma_{h}+\Delta \tau_{x y}+\left(\Delta \sigma_{y}+\sigma_{v}\right) \sin \alpha\right) \sin \theta\right)^{2} \\
& +\Delta \tau_{x y}^{2}-2 \mu\left(\left(\Delta \sigma_{x}+\sigma_{H}+\left(\Delta \sigma_{y}+\sigma_{v}\right) \cos \alpha\right) \sin \theta\right. \\
& \left.+\left(\sigma_{h}+\Delta \tau_{x y}+\left(\Delta \sigma_{y}+\sigma_{v}\right) \sin \alpha\right) \cos \theta\right) \\
& \left(\Delta \sigma_{x}+\sigma_{H}+\left(\Delta \sigma_{y}+\sigma_{v}\right) \cos \alpha\right) \cos \theta \\
& \left.+\left(\sigma_{h}+\Delta \tau_{x y}+\left(\Delta \sigma_{y}+\sigma_{v}\right) \sin \alpha\right) \sin \theta\right) \\
& +\left(\Delta \sigma_{x}+\sigma_{H}+\left(\Delta \sigma_{y}+\sigma_{v}\right) \cos \alpha\right) \cos \theta \\
& \left.+\left(\sigma_{h}+\Delta \tau_{x y}+\left(\Delta \sigma_{y}+\sigma_{v}\right) \sin \alpha\right) \sin \theta\right) \Delta \tau_{x y} \\
& +\Delta \tau_{x y}\left(\Delta \sigma_{x}+\sigma_{H}+\left(\Delta \sigma_{y}+\sigma_{v}\right) \cos \alpha\right) \sin \theta \\
& \left.\left.\left.+\left(\sigma_{h}+\Delta \tau_{x y}+\left(\Delta \sigma_{y}+\sigma_{v}\right) \sin \alpha\right) \cos \theta\right)\right)\right]
\end{aligned}
$$

The analysis of the above expressions shows that $U^{e}$ is not only related to buried depth $\mathrm{H}$, mining thickness $M$ or physical and mechanical properties of coal body but also related to the concentrated stress caused by cantilever beam structure on coal seam [18].

\section{Controllable Factors That Reduce the Degree of Elastic Strain Energy Accumulation}

By changing the load stress on the coal seam, the thickness of the main roof and direct roof has a significant impact on the elastic strain energy of the coal body in zone A-B-C. It can be obtained from formula (11) that the trend of $U^{e}$ is with the thickness of the main roof:

Select the actual geological conditions and parameters of a coal mine: buried depth $H$ is $960 \mathrm{~m}$; elastic modulus $E$ is 2.2 GPa; Poisson's ratio $\mu$ is 0.3 ; the mining thickness $M$ is $6.2 \mathrm{~m}$; the internal friction angle $\varphi$ is $42^{\circ}$.

As illustrated in Figure 5(a)-5(c), elastic strain energy $U^{e}$ does not increase blindly with the increase of main roof rock mass's cohesion. There is a tendency that $U^{e}$ increases first and then decreases with $C$, when $C$ increases from 1.0 $\mathrm{MPa}$ to $1.7 \mathrm{MPa}$, and $U^{e}$ increases from $1.604 \times 10^{6} \mathrm{~J}$ to $1.647 \times 10^{6} \mathrm{~J}$. Then, with the increase of $C$ from $1.7 \mathrm{MPa}$ to $2.5 \mathrm{MPa}, U^{e}$ decreases from $1.647 \times 10^{6} \mathrm{~J}$ to $1.574 \times 10^{6} \mathrm{~J}$ with it.
From the overall trend in Figure 5, the increase in $C$ of main roof rock mass causes the suspension length of cantilever beam structure to gradually transform from "Stress source objection" to "Stress endurance objection." Therefore, shortening the suspension length of cantilever beam structure can reduce the degree of elastic strain energy accumulation to a certain extent.

Considering the relationship between the thickness of main roof and $U^{e}$, elastic strain energy increases with the addition of thickness from beginning to end and oversized thickness of main roof strata structure is definitely an adverse condition to reduce the accumulation of $U^{e}$ to cut down the hazard of rockbursts. As shown in Figure 5(b), when thickness increases from $5 \mathrm{~m}$ to $15 \mathrm{~m}, U^{e}$ increases $1.146 \times 10^{6} \mathrm{~J}$ from $9.3 \times 10^{5} \mathrm{~J}$ to $2.076 \times 10^{6} \mathrm{~J}$. With similar patterns, tensile strength $R_{T}$ affects $U^{e}$ linearly. When $R_{T}$ increases from $1 \mathrm{MPa}$ to $2 \mathrm{MPa}, U^{e}$ increases from $7.07 \times 10^{5} \mathrm{~J}$ to $1.596 \times 10^{6} \mathrm{~J}$.

Generally, undermining the main roof structure and reducing the weight of the cantilever beam structure is the most effective method to mitigate the hazard of rockbursts from the source. At present, presplitting blasting and water jet cutting roof are both feasible methods to implement. Considering the dangerousness of presplitting blasting, some mine commands prohibit the use of presplitting blasting with emulsified explosive. Therefore, water jet and hydraulic fracturing become the focus method to prevent rockbursts. 


\section{Construction Scheme to Prevent Rockburst Measures for Directional Presplitting Cutting Main Roof Using the Water Jet}

Hydraulic fracturing was initiated in the oil industry and is now being used in the cave mining industry diffusely as a preconditioning method and for solving the problem of mine dynamic-seismic problems. Hydraulic fracturing had its first commercial application in 1949 (Clark 1949). When hydraulic fracturing is used in cave mining for preconditioning, boreholes are drilled from the surface or subsurface excavations into the rock mass to create multiple transverse hydraulic fractures along each borehole. These artificial fractures aim to improve coal body cave-ability below the hard and thick rock strata and reduce fragmentation sizes in the rock strata [17-20, 22].

In order to create orientation-controllable hydraulic fractures in the hard roof rock mass, here, we proposed an approach to use water jet to create a prefracturing surface considering in situ stress effect in the first place. Then, we use a packer to isolate the position to be fractured and inject high-pressure fracturing fluid to fracture the hard rock strata continuously; here, it is termed water jet-hydraulic fracturing method $[23,24]$.

5.1. Hydraulic Fracture Reorientation under the Influence of In Situ Stress Effect. The in situ principal stress system can be defined in terms of three orthogonal stresses: $\sigma_{v}, \sigma_{H}, \sigma_{h}$. The geological fault systems are defined (Jaeger and Cook. 1969) on the basis of Coulomb-Mohr theories of shear failure. According to the relative magnitudes of $\sigma_{v}, \sigma_{H}, \sigma_{h}$, there are three stress regimes: Normal-slip fault $\left(\sigma_{v}>\sigma_{H}>\sigma_{h}\right)$, Reverse fault $\left(\sigma_{v}>\sigma_{H}>\sigma_{h}\right)$, and Transcurrent fault $\left(\sigma_{v}>\sigma_{H}>\sigma_{h}\right)$ are defined as illustrated in Figure 6.

When a bore hole is drilled into the rock mass formation, rock mass stressed by the three stress regimes is transformed. In addition, the surface orientation of main hydraulic fracture is severely affected by the difference between three in situ principal stresses and the types of three regimes. The influence relationship is shown in Figure 6 at the right column.

5.2. Hydraulic Fracture Initiation Criteria. According to rock fracture mechanics criterion, the fracture initiates at the bore hole wall when a Type I fracture emerges [21, 25]. The parameters in the in situ stress coordinate system are converted into the parameters of the borehole azimuth coordinate system as shown in Figure 7 through the following formulas:

$$
\begin{aligned}
& \left\{\begin{array}{l}
\sigma_{x}=\left[\sigma_{h} \cos ^{2}(\beta)+\sigma_{H} \sin ^{2}(\beta)\right] \cos ^{2}(\psi)+\sigma_{v} \sin ^{2}(\psi), \\
\sigma_{y}=\sigma_{h} \sin ^{2}(\beta)+\sigma_{H} \cos ^{2}(\beta), \\
\sigma_{z}=\left[\sigma_{h} \cos ^{2}(\beta)+\sigma_{H} \sin ^{2}(\beta)\right] \sin ^{2}(\psi)-\sigma_{v} \cos ^{2}(\psi), \\
\tau_{y z}=0.5\left(\sigma_{H}-\sigma_{h}\right) \sin 2 \beta \sin \psi, \\
\tau_{z x}=0.5\left[\sigma_{h} \cos ^{2}(\beta)+\sigma_{H} \sin ^{2}(\beta)-\sigma_{v}\right] \sin 2 \beta, \\
\tau_{x y}=0.5\left(\sigma_{H}-\sigma_{h}\right) \sin 2 \beta \cos \psi
\end{array}\right. \\
& \left\{\begin{array}{l}
\sigma_{r}=P_{w}, \\
\sigma_{\theta \theta}=\sigma_{x}+\sigma_{y}-2\left(\sigma_{x}-\sigma_{y}\right) \cos 2 \theta-P_{w}=4 \tau_{x y} \sin 2 \theta, \\
\sigma_{z \theta}=\sigma_{z}-2 v\left(\sigma_{x}-\sigma_{y}\right) \cos 2 \theta-4 v \tau_{x y} \sin 2 \theta, \\
\tau_{r \theta}=\tau_{r z}=0, \\
\tau_{\theta z}=2\left(-\tau_{x z} \sin \theta+\tau_{y z} \cos \theta\right) .
\end{array}\right.
\end{aligned}
$$

Based on formulas (12), (13) and the mechanical model in Figure 7 , fractures initiated at an azimuth $\theta_{c r}$ with the minimum fluid pressure $P_{w f}$ can be determined by

$$
P_{w f}=\sigma_{x}+\sigma_{y}-2\left(\sigma_{x}-\sigma_{y}\right) \cos 2 \theta_{c r}-4 \tau_{x y} \sin 2 \theta-\frac{\tau_{\theta z_{c r}}^{2}}{\sigma_{z \theta_{c r}}} .
$$

The fracturing fluid injection pressure of pump during construction can be calculated by the formulas as aforementioned.

\section{Hydraulic Fracturing Cutting Main Roof System}

The hydraulic fracturing technology equipment system consisted of a bench frame, a $100 \mathrm{MPa}$ plunger pump, a filter, an in-line pump, and a $250 \mathrm{~kW}$ electric motor. All the abovementioned electronics parts have explosion-proof enclosures with coal mine safety certification, as shown in Figure 8 .

The loading rate of fluid pressure could be controlled by the electric control system from 0 to $100 \mathrm{MPa}$. In addition, the other parameters of the hydraulic fracturing system are as follows: motor speed $=1480 \mathrm{r} / \mathrm{min}$, rate flow $=116 \mathrm{~L} / \mathrm{min}$, and piston diameter $=30 \mathrm{~mm}$. According to the above parameters and variables, the water pressure in the bore hole at the fracturing position can be calculated, and the pressure at the hole of the water jet can be determined, similarly.

After the low pressure water is pressurized through the hydraulic fracturing system, the high-pressure water flows through the jet (Figure 9) to form a high-energy waterline, which can cut the rock mass into a fracture surface by 

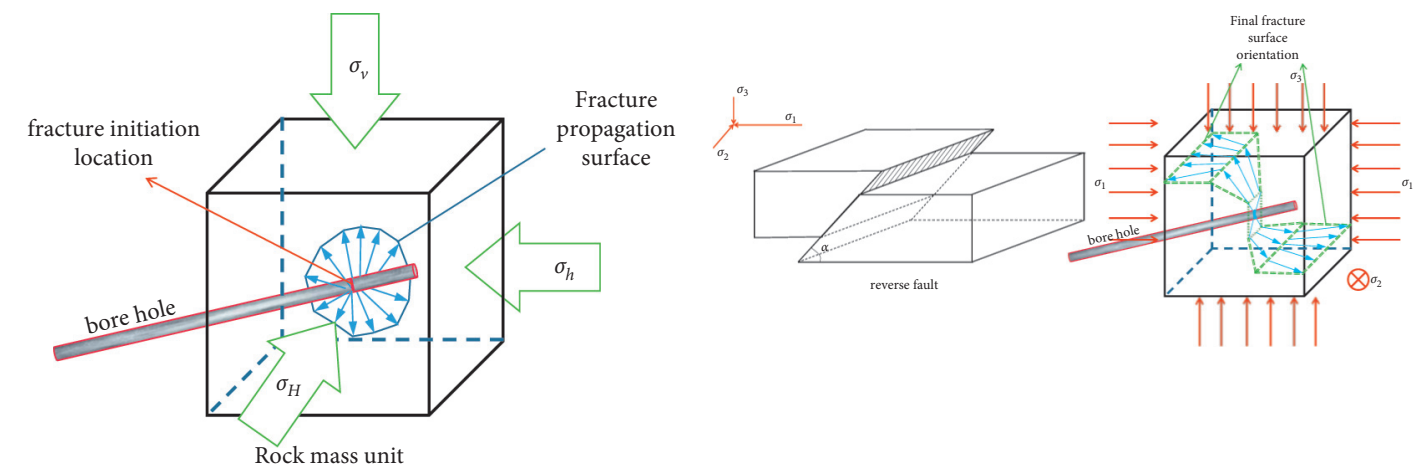

An arbitrarily oriented bore hole under in-situ stress
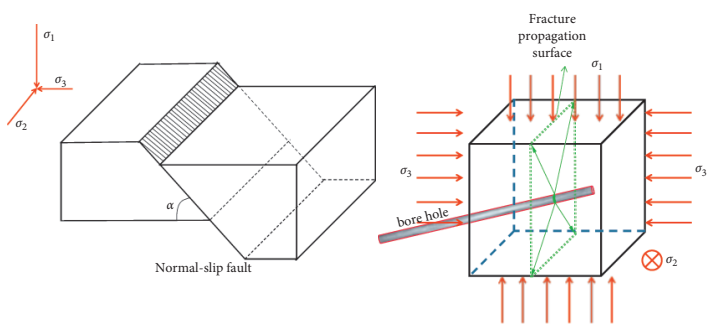

(a)
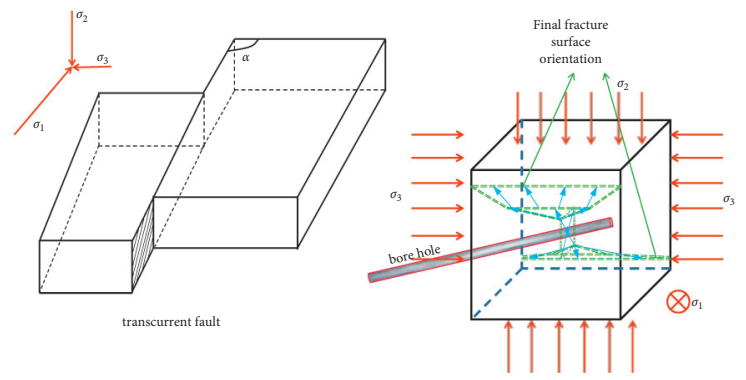

(c)

Figure 6: Reorientation effect of in situ stress on fracture propagation. (a) Normal-slip fault fracture propagation. (b) Reverse fault fracture propagation. (c) Transcurrent fault fracture propagation.

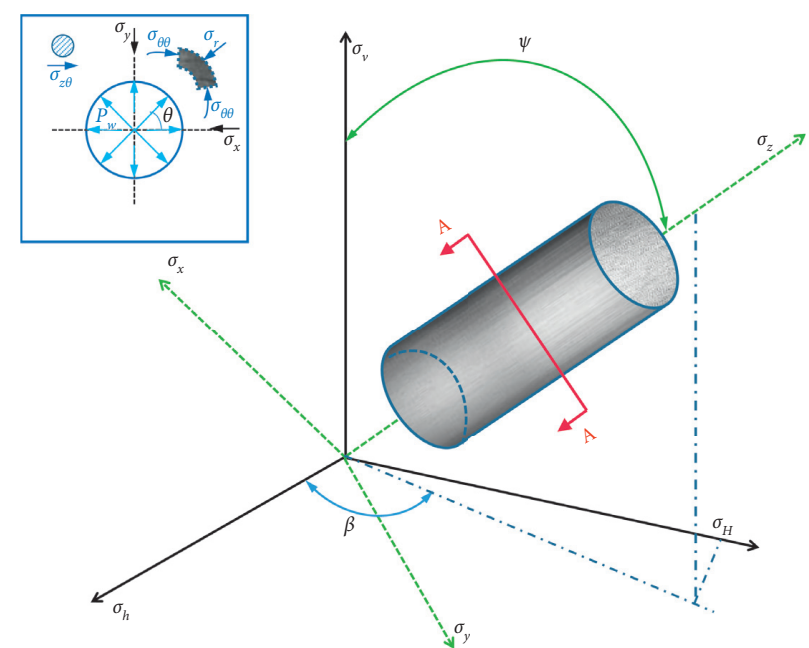

Figure 7: Mechanical model of fracture initiation criterion. 


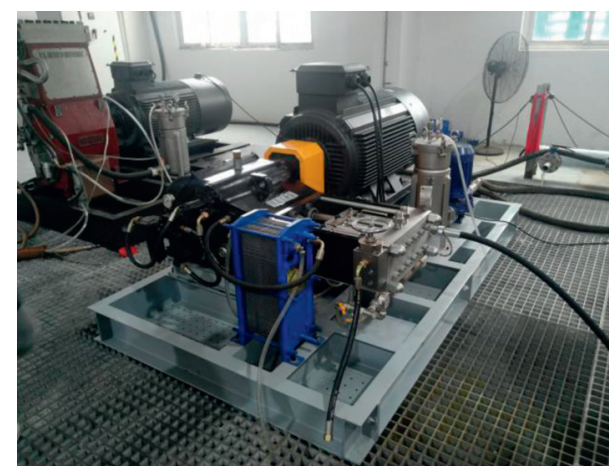

(a)

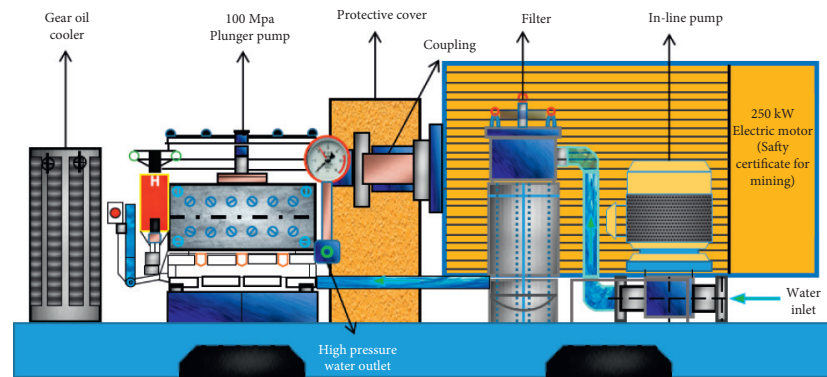

(b)

FIGURE 8: Assembly drawing of high-pressure water pump. (a) Real picture of equipment. (b) Function diagram of each part of equipment.

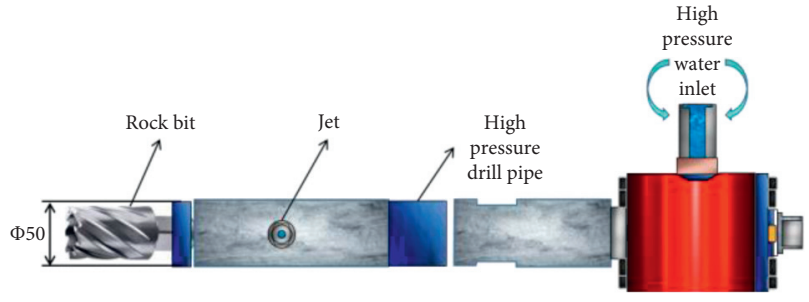

FIGURE 9: High-pressure water jet.

whirling bore through the combined effects of erosion, stretching, shearing, and grinding [26-31].

Horizontal and vertical cross-sections of hard roof rock formations cut by water jet process are shown in Figures 10 and 11.

After the water jet cutting the preset fracture surface operation is finished, pull out the drill pipe and water jet. Send the packer into the preset fracture surface position, and perform high-pressure hydraulic fracturing.

Consider the typical geological conditions of rockburst coal mines in Shandong province. Select the average geology parameter as in Table 1.

By taking the geological conditions parameters as the value in Table 1, the relationship between the maximum principal stress $\sigma_{1}$, elastic strain energy $U^{e}$, and the distance from the coal wall (which is in the front of the working face) to the calculated position in the deep coal seam $I$ is obtained, as shown in Figure 12.

From the regular pattern shown in Figure 12, status A is from 0 to $15 \mathrm{~m}$ approximately, status $\mathrm{B}$ is from 15 to $25 \mathrm{~m}$, and status $\mathrm{C}$ is from 25 to $40 \mathrm{~m}$. The peak value of $\sigma_{1}$ reaches $36.4 \mathrm{MPa}$, and the maximum value of $U^{e}$ is $1.3 \times 10^{6} \mathrm{~J}$. The changing law of $\sigma_{1}$ from status A to $b$ to $c$ is increasing first and finally decreasing to initial situation stress. Elastic strain energy reaches the maximum in the junction of status B and status C.

The fracture initiation fluid pressure is calculated by formula (14), combined with the field parameters, where $P_{w f}$ should not be less than $36.5 \mathrm{MPa}$ to overcome the effects of three principle stresses and make the preset fracture surface to propagate. Obviously, the operating pressure of the highpressure plunger pump can fully meet this criteria threshold.

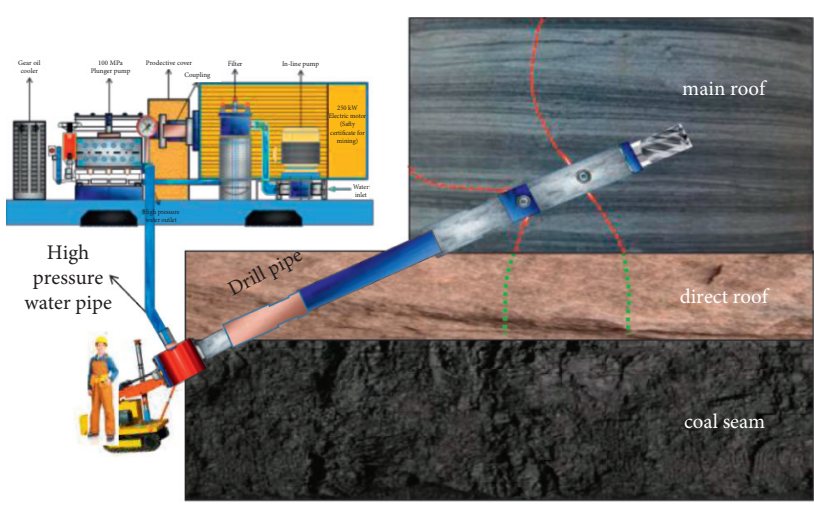

FIgURE 10: Schematic diagram of water jet cutting top plate process.

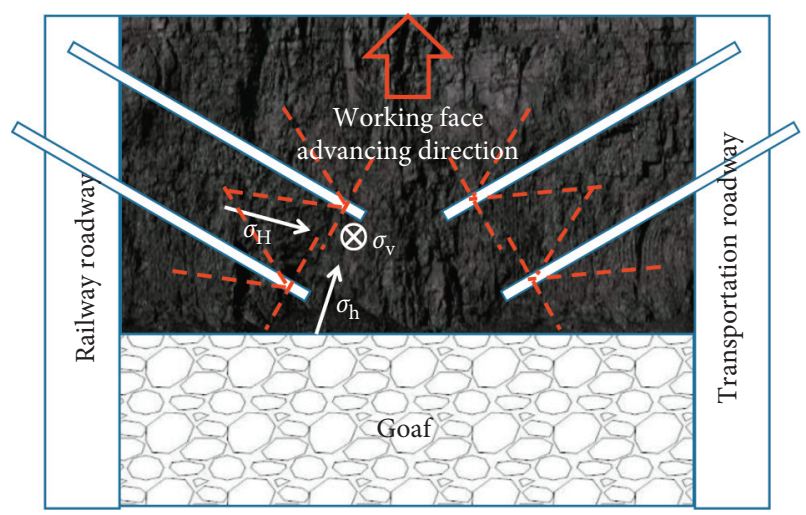

FIgURE 11: Schematic diagram of drilling layout plan.

For this case, the thickness $h$ of main roof rock mass is $5 \mathrm{~m}$. The length $L_{T}$ of main roof rock mass is $10 \mathrm{~m}$. When the hydraulic fracturing process creates a horizontal fracture surface in the main roof formation, the thickness $h$ ' of the main roof formation is reduced to $2.5 \mathrm{~m}$. Under these circumstances, reformed relationship between $\sigma_{1}$, elastic strain energy $U^{e}$, and $I$ is shown in Figure 13.

As shown in the figure, status $\mathrm{A}$ is from 0 to $8 \mathrm{~m}$ approximately, status $B$ is from 8 to $17 \mathrm{~m}$, and status $C$ is from 17 to $30 \mathrm{~m}$. The peak value of $\sigma_{1}, U^{e}$ reaches $34.7 \mathrm{MPa}$ and 
TABLE 1: Main parameters of geological conditions and technical conditions.

\begin{tabular}{|c|c|c|c|}
\hline Name of parameters & Symbols & Unit & Value \\
\hline Maximum in situ horizontal stress & $\sigma_{H}$ & $\mathrm{MPa}$ & 200 \\
\hline Maximum in situ horizontal stress & $\sigma_{h}$ & MPa & 215 \\
\hline Vertical in situ stress & $\sigma_{v}$ & $\mathrm{MPa}$ & 250 \\
\hline Buried depth & $H$ & $\mathrm{~m}$ & 1000 \\
\hline Main roof tensile strength & $\sigma_{t}$ & $\mathrm{MPa}$ & 2 \\
\hline Poisson's ratio of the main roof rock mass formation & $\mu$ & Dimensionless & 0.2 \\
\hline Internal friction angle & $\varphi$ & ${ }^{\circ}$ & 42 \\
\hline Elasticity modulus & $E$ & $\mathrm{GPa}$ & 2.58 \\
\hline Stress concentration coefficient & $K$ & Dimensionless & 2.5 \\
\hline Average formation volume force & $\gamma$ & $\mathrm{N} / \mathrm{m}^{3}$ & 25000 \\
\hline Density of the main roof rock mass & $\rho$ & $\mathrm{Kg} / \mathrm{m}^{3}$ & 2630 \\
\hline
\end{tabular}

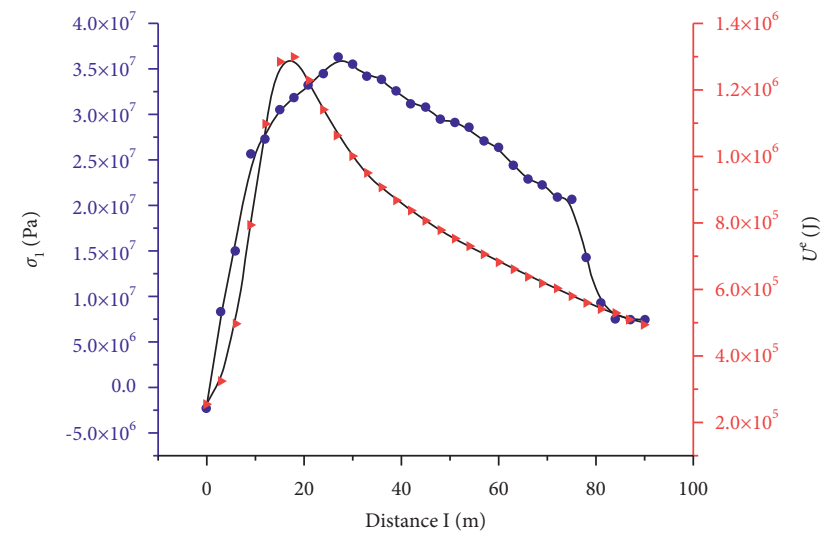

FIGURE 12: Relationship between the maximum principal stress $\sigma_{1}$, elastic strain energy $U^{e}$ and $I$.

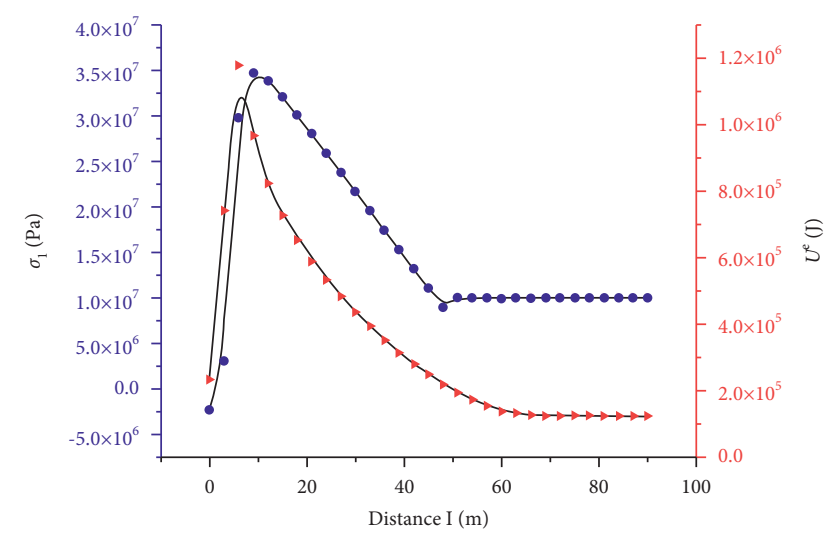

FIGURE 13: Relationship between $\sigma_{1}, U^{e}$, and $I$ when the main roof is cut by hydraulic fracturing surface horizontally.

$1.1732 \times 10^{6} \mathrm{~J}$, respectively. Whether the peak value or the average value of $\sigma_{1}$ and $U^{e}$ is obviously less than the value before the hydraulic fracturing process was conducted.

When the hydraulic fracturing process creates a vertical fracture surface in the main roof formation, the length $L_{T}$ of the main roof formation is reduced to $5 \mathrm{~m}$. In these conditions, the new relationship between $\sigma_{1}$, elastic strain energy $U^{e}$, and $I$ is shown in Figure 14 .

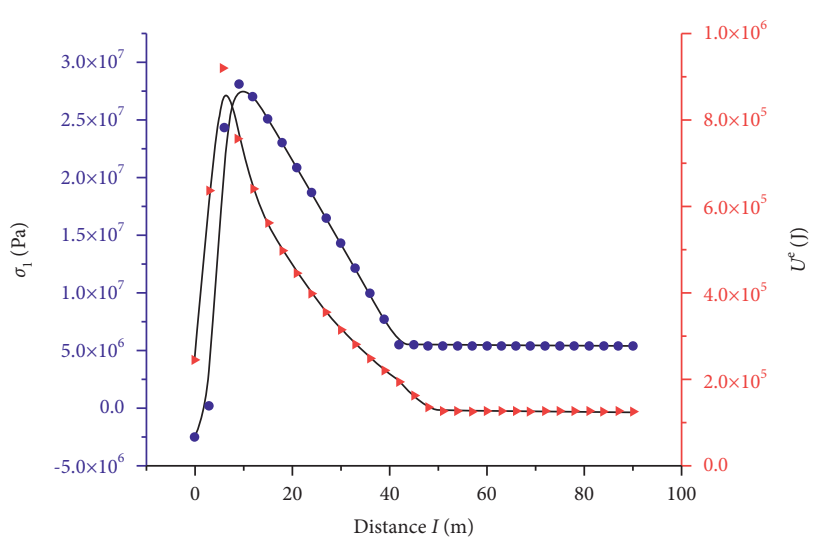

FIGURE 14: Relationship between $\sigma_{1}, U^{e}$, and $I$ when the main roof is cut by hydraulic fracturing surface vertically.

The maximum principal stress and elastic energy values at each position in front of the working face are presented in Figure 14. The length of statuses A, B, and C is not much different from that of horizontal hydraulic fracturing surface, which is $0-7.3 \mathrm{~m}, 7.3-16.8 \mathrm{~m}$, and $16.8-27 \mathrm{~m}$, respectively. And compared to creating a horizontal fracture surface in the main roof formation, the vertical hydraulic fracturing surface method reduces the peak value of $\sigma_{1}$ from 34.7 MPa to $26.84 \mathrm{MPa}$. The peak value of $U^{e}$ is reduced from $1.1732 \times 10^{6} \mathrm{~J}$ to $9.32 \times 10^{5} \mathrm{~J}$ significantly.

\section{Conclusions}

The following conclusions can be drawn from this study:

(1) Based on the elastic-plastic mechanics, materials mechanics, and research results of experts and scholars on rockburst theory previously, the analytical formula of elastic strain energy in front of the working face is derived, whereby the partition and its length of A-B-C coal body "chain-type" energy transfer process can be obtained. Among the three statuses, $\mathrm{B}$ as the rockburst resistance zone and $\mathrm{C}$ as the rockburst starting zone have decisive influences on the occurrence and transmission process of rockbursts. 
(2) By analyzing the elastic strain energy calculation analytical formula found that the integrity, strength properties and thickness of the main roof rock mass have significant influences on the stockpile and accumulation of the elastic strain energy. Therefore, reducing the above three properties of the main roof rock formation has become a breakthrough to prevent rockbursts [32, 33].

(3) According to three types of in situ stress and different borehole layout azimuths, hydraulic fracturing initiation criteria are obtained. The calculation results show that our plunger high-pressure water pump can meet the minimum threshold pressure to fracture the main roof rock mass and maintain the continuous propagation of the fracture surface.

(4) The theoretical calculation values of the different hydraulic fracturing construction methods, horizontal fracturing and vertical fracturing, are compared. As a result, the vertical hydraulic fracturing method should be emphasized. The vertical hydraulic fracturing method has the most obvious effect of reducing the elastic strain energy to decrease the hazard of rockbursts, and this method is also convenient to be implemented in construction.

\section{Data Availability}

The experimental and analytical calculation results data used to support the findings of this study are included within the article.

\section{Conflicts of Interest}

The authors declare that there are no conflicts of interest regarding the publication of this paper.

\section{Acknowledgments}

This work was supported by the National Natural Science Foundation of Surface Project of China (No. 51774289) and the National Natural Science Foundation of the Youth Science Foundation of China (No. 51404270).

\section{References}

[1] L. P. Dai, Y. S. Pan, Z. H. Li et al., "Quantitative mechanism of roadway rockbursts in deep extra-thick coal seams: theory and case histories," Tunnelling and Underground Space Technology, vol. 111, pp. 103-116, 2021.

[2] X. Zhang, Y. Jiang, L. Chen, X. Wang, N. Golsanami, and L. Zhou, "Anti-plane seismic performance of a shallow-buried tunnel with imperfect interface in anisotropic half-space," Tunnelling and Underground Space Technology, vol. 112, Article ID 103906, 2021.

[3] X. Zhang, Y. Jiang, G. Wang, Y. Cai, and T. Iura, "Threedimensional seismic performance of mountain tunnel with imperfect interface considering $\mathrm{P}$ wave," Tunnelling and Underground Space Technology, vol. 108, Article ID 103720, 2021.
[4] A. C. Adoko, C. Gokceoglu, L. Wu, and Q. J. Zuo, "Knowledge-based and data-driven fuzzy modeling for rockburst prediction," International Journal of Rock Mechanics and Mining Sciences, vol. 61, pp. 86-95, 2013.

[5] N. G. Cook, E. Hoek, J. P. G. Pretorius, W. D. Ortlepp, and M. D. G. Salamon, "Rock mechanics applied to the study of rockbursts," Journal of the Southern African Institute of Mining and Metallurgy, vol. 66, pp. 435-528, 1966.

[6] N. G. W. Cook, "The failure of rock," International Journal of Rock Mechanics and Mining Science \& Geomechanics Abstracts, vol. 2, no. 4, pp. 389-403, 1965.

[7] X. Wang, N. Wu, L. Hong, and Y. Yan, "Influence of joint angle on the instability failure characteristics and AE evolution law of underground caverns," European Journal of Environmental and Civil Engineering, pp. 1-18, 2020.

[8] X. Wang and F.-B. Meng, "Statistical analysis of large accidents in China's coal mines in 2016," Natural Hazards, vol. 92, no. 1, pp. 311-325, 2018.

[9] P. K. Kaiser and M. Cai, "Design of rock support system under rockburst condition," Journal of Rock Mechanics and Geotechnical Engineering, vol. 4, no. 3, pp. 215-227, 2012.

[10] J. F. Pan, Y. Ning, D. B. Mao, H. Lan, and Y. Peng, "Theory of rockburst start-up during coal mining," Rock Mechanics and Rock Engineering, vol. 31, pp. 586-596, 2012.

[11] Y. S. Pan, L. P. Dai, G. Z. Li, G. Z. Li, and Z. H. Li, "Study on compound disaster of rock burst and roof falling in coal mines," Journal of China Coal Society, vol. 39, pp. 471-475, 2021.

[12] Q. X. Qi, S. B. Chen, H. X. Wang, D. B. Mao, and Y. X. Wang, "Study on the relations among coal bump, rockburst and mining tremor with numerical simulation," Rock Mechanics and Rock Engineering, vol. 11, pp. 1852-1858, 2003.

[13] H. P. Xie, F. Gao, Y. Ju et al., "Quantitative definition and investigation of deep mining," Journal of China Coal Society, vol. 40, pp. 1-10, 2015.

[14] H. P. Xie, H. W. Zhou, D. J. Xue, H. W. Wang, R. Zhang, and F. Gao, "Research and consideration on deep coal mining and critical mining depth," Journal of China Coal Society, vol. 37, pp. 535-542, 2012.

[15] W. D. Ortlepp and T. R. Stacey, "Rockburst mechanisms in tunnels and shafts," Tunnelling and Underground Space Technology, vol. 9, no. 1, pp. 59-65, 1994.

[16] M. He, F. Ren, and D. Liu, "Rockburst mechanism research and its control," International Journal of Mining Science and Technology, vol. 28, no. 5, pp. 829-837, 2018.

[17] C. H. Dowding and C.-A. Andersson, "Potential for rock bursting and slabbing in deep caverns," Engineering Geology, vol. 22, no. 3, pp. 265-279, 1986.

[18] Y. S. Zhao, Z. C. Feng, and Z. J. Wan, "Least energy principle of dynamical failure of rock mass," Chinese Journal of Rock Mechanics and Engineering, vol. 121, pp. 1781-1783, 2003.

[19] J.-A. Wang and H. D. Park, "Comprehensive prediction of rockburst based on analysis of strain energy in rocks," Tunnelling and Underground Space Technology, vol. 16, no. 1, pp. 49-57, 2001.

[20] J. Pan, F. Ren, and M. Cai, "Effect of joint density on rockburst proneness of the elastic-brittle-plastic rock mass," Shock and Vibration, vol. 2021, Article ID 5574325, 9 pages, 2021.

[21] Z. Q. Wang, C. Wu, J. Q. Luo et al., "Research on Instability Mechanism and Control of Sectional Coal Pillars in ultrathick Coal Seams in Fully-mechanized Mining Faces," J/OL. China Coal Society, vol. 40, no. 8, Article ID 51704155, 2021.

[22] J. F. Pan, W. T. Ma, S. H. Liu, and J. M. Gao, "Test of Directional Pre-Cracking and Anti-scouring Technology for 
Hard Roof Water Jet Prefabricated Slot," J/OL.Chinese Journal of Rock Mechanics and Engineering, vol. 40, no. 8, p. 1056, 2020.

[23] H. P. Kang, J. Lin, and X. Zhang, "Research and application of in-situ stress measurement methods in deep mines," Chinese Journal of Rock Mechanics and Engineering, vol. 4, pp. 929-933, 2007.

[24] S. H. Yan, Y. Ning, L. J. Kang, Y. W. Shi, Y. G. Wang, and Y. F. Li, "The Mechanism and Experimental Research on the Treatment of Hard Roof by Hydraulic Fracturing," Journal of China Coal Society, vol. 4, pp. 34-37, 2000.

[25] M. M. Hossain, M. K. Rahman, and S. S. Rahman, "Hydraulic fracture initiation and propagation: roles of wellbore trajectory, perforation and stress regimes," Journal of Petroleum Science and Engineering, vol. 27, no. 3-4, pp. 129-149, 2000.

[26] M. K. Hubbert and D. G. Willis, "Mechanics of hydraulic fracturing," Transactions of the AIME, vol. 210, no. 1, pp. 153-168, 1957.

[27] B. Huang and J. Liu, "Experimental investigation of the effect of bedding planes on hydraulic fracturing under true triaxial stress," Rock Mechanics and Rock Engineering, vol. 50, no. 10, pp. 2627-2643, 2017.

[28] Q. He, F. T. Suorineni, and J. Oh, "Strategies for creating prescribed hydraulic fractures in cave mining," Rock $\mathrm{Me}$ chanics and Rock Engineering, vol. 50, no. 4, pp. 967-993, 2017.

[29] J. Wang, H. P. Xie, and C. B. Li, "Anisotropic failure behaviour and breakdown pressure interpretation of hydraulic fracturing experiments on shale," International Journal of Rock Mechanics and Mining Sciences, vol. 142, Article ID 104748, 2021.

[30] M. G. Qian, X. X. Miao, and J. L. Xu, "Theoretical research on the key stratum in strata control," Journal of China Coal Society, vol. 4, pp. 2-7, 1996.

[31] Q. H. Qian, "The definition, Mechanism, classification and quantitative prediction model of rock burst and rock burst," Journal of Rock and Soil Mechanics, vol. 35, no. 1, pp. 1-6, 2014.

[32] T. Ito, K. Evans, K. Kawai, and K. Hayashi, "Hydraulic fracture reopening pressure and the estimation of maximum horizontal stress," International Journal of Rock Mechanics and Mining Sciences, vol. 36, no. 6, pp. 811-826, 1999.

[33] J. Yang, M. Fall, and G. Guo, "A three-dimensional hydromechanical model for simulation of dilatancy controlled gas flow in anisotropic claystone," Rock Mechanics and Rock Engineering, vol. 53, no. 9, pp. 4091-4116, 2020. 